DE DE GRUYTER

OPEN

DOI 10.1515/pesd-2015-0006

PESD, VOL. 9, no. 1, 2015

\title{
THE PHYSICO-MECHANICAL CHARACTERISTICS OF THE CLAYS IN AND AFTER DOPING WITH METAL OXIDE $\mathrm{AL}_{2} \mathrm{O}_{3}$ IN THE REGION OF FEZ (MOROCCO)
}

\author{
Laila Mesrar $^{1}$, Mariam Akdim ${ }^{1}$, Mohamed Lakrim ${ }^{1}$, Omar El Aroussi $^{1}$, \\ Iatimad Akhrif ${ }^{1}$, Raouf Jabrane ${ }^{1}$
}

Key words: Clay-Doping, marl, alumina oxide, X-ray, X-ray fluorescence, electric property.

\begin{abstract}
Miocene marl is one of the widespread geological substrates in Fez vicinity (Central Morocco). In this study we proceed by a physicochemical characterization of the marl after doping with metal oxides, by various analytical techniques, namely the $\mathrm{X}$-ray fluorescence, the mineralogical analysis, and dielectric property. The doping of these marl was conducted by solid oxides of $\mathrm{Al}_{2} \mathrm{O}_{3}$ at different percentages $(5 \%, 10 \%$ and $15 \%)$. The results of chemical analysis showed the $\mathrm{Al}_{2} \mathrm{O}_{3}$ increase during doping. So, the mineralogical analysis of doped clays shows peaks' increases for kaolin. The marl doped acquired the property of their good electrical conductor compared to crass marl.
\end{abstract}

\section{Introduction}

The marl's minerals are abundant untreated material in several areas worldwide. They are often under-valued for human use. However, due to demands of the society in terms of sustainability and energy saving, the valuation of these resources to develop new materials, most environmentally friendly has become a concern both scientific and industrial aims.

Ceramics are the growing research to obtain materials with good chemical stability and good hot properties (Jouenne, 1984). The balance between these properties and industrial requirements allowed clay materials uses at craft departure (pottery, tile), to progress towards high-tech applications such as electrical and thermal insulation, electric candle, sound insulation, etc. (Louet, 2003).

\footnotetext{
${ }^{1}$ Department of Earth Science, Georesources and Environment Laboratory, Science and Technology Faculty, Sidi Mohamed Ben Abdellah University, BP.2202, Route Imouzzer, Fez, Morocco
} 
The behavior of the doping $\left(\mathrm{Al}_{2} \mathrm{O}_{3}\right)$, which has more scientific research interest, has been a renewed interest since 1980 (Fabri and al, 1985) with the emergence of alumina very high purity. The present study focuses on the influence of doping on the microstructure of marl, based on the results obtained by X-ray fluorescence and X-Ray.

In this perspective, the doping of the marl clays with alumina oxide could increase the added value of the clay used in the technology and building industry (Esharghawi, 2009).

One of the major problems encountered by users of these materials is the fragility and high shrinkage induced by cookery causing defects in the briquette (Mesrar and al, 2013), and can go until it bursts. To improve performance, efficiency and the quality in the manufacture of this marl, we opted doping dry voice of these materials by the alumina oxide it has considering percentages of 5 , 10 and $15 \%$.

The findings allow us to conceive and suggest new improvements of the physicochemical and mechanical parameters for marl, to rise the value and use of this low cost material.

\section{Materials and Methods}

In the aim to study the homogeneity and the concentration of $\mathrm{Al}_{2} \mathrm{O}_{3}$ incorporated in the clay sheets, several analysis techniques were used:

- Chemical analysis: the quantitative chemical analysis of clays was performed by X-ray fluorescence spectrometry (WD-XRF) spectrometer type Axios sequential brand Panalytical. This analysis was made after grinding the material and taking 10 $\mathrm{g}$ of each sample. Then we took $10 \mathrm{~g}$ of each powder sample and pressed it in a hydraulic press, in order to make the pellets.

-X-ray diffraction DRX study was done with the Philips diffractometer XPERT-PRO" PW 3064, with the Ka1,2 radiation of copper. X-ray diffraction (XRD) data were obtained using oriented samples prepared on glass slides in the $2 \theta$ range of $2-40^{\circ}$ at a scanning speed of $2^{\circ} \min -1$.

-The geotechnical property was performed in the laboratory of geosciences and environment at the FST (Sidi Mohamed Ben Abdellah University). The evaluation of plasticity was performed by the Casagrande method (Mesrar et al., 2013). The Atterberg limits are conventional physical constants indicating the clay transition from plastic to liquid state (WL) and from the plastic to solid state (WP). The plasticity index, which represents the difference between the liquid limit and plastic limit, defines the extent of the plastic field of clay.

-Bricks production is carried out using a metal mold, provided for the operation. It has a length of $50 \mathrm{~mm}$ and a width of $10 \mathrm{~mm}$. Bricks are previously dried in the open air until the stabilization of the withdrawal. They are fired in an 
The physico-mechanical characteristics of the clays in and after doping with metal oxide $\mathrm{Al}_{2} \mathrm{O}_{3} 105$

electric oven programmable to the temperatures of $900^{\circ} \mathrm{C}$, with a bake cycle of 30 minutes and a bearing of one hour and a half to the maximum firing temperature. The rate temperature of firing rise $10^{\circ} \mathrm{C} / \mathrm{min}$.

The parameters resulting from the bricks firing are observed as the materials withdrawal along drying and firing, the ignition loss, and the mechanical resistance to compression.

\section{Results and Discussion}

2.1. Chemical analysis. We note that the predominant components in all samples are silica and alumina, respectively, for the raw clay and doped (Table.1).

The easiest way to determine the influence of a doping is to make measurements of essay material doped before and after doping.

Thus, analysis of the chemical composition by XRF clays doped with $\mathrm{Al}_{2} \mathrm{O}_{3}$, reveals a significant enrichment in alumina. Its concentration increases as the doping level is increasing.

Tab.1: Percentage major elements of our crude marl (Z1) and doping with $\mathrm{Al}_{2} \mathrm{O}_{3}$.

\begin{tabular}{|l|c|c|c|c|c|c|c|c|c|c|c|}
\hline Sample & $\mathrm{SiO}_{2}$ & $\mathrm{Al}_{2} \mathrm{O}_{3}$ & $\mathrm{CaO}$ & $\mathrm{Fe}_{2} \mathrm{O}_{3}$ & $\mathrm{MgO}$ & $\mathrm{K}_{2} \mathrm{O}$ & $\mathrm{Na}_{2} \mathrm{O}$ & $\mathrm{Ti}_{2} \mathrm{O}$ & $\mathrm{MnO}_{2}$ & $\mathrm{SO}_{3}$ & P.F \\
\hline $\mathrm{Z1}$ crude (brut) & 44.9 & 15.1 & 6.64 & 6.49 & 3.08 & 1.10 & 0.80 & 0.37 & 0.20 & 0.26 & 18.5 \\
\hline $\mathrm{Z1} \mathrm{doped} \mathrm{with} \mathrm{5 \%}$ & 42.5 & 16.6 & 5.89 & 5.86 & 2.85 & 1.02 & 0.78 & 0.31 & 0.19 & 0.24 & 21.4 \\
\hline $\mathrm{Z1} \mathrm{doped} \mathrm{with} 10 \%$ & 42.9 & 19.6 & 5.88 & 6.34 & 2.97 & 1.06 & 0.81 & 0.33 & 0.20 & 0.26 & 17.1 \\
\hline Z1 doped with15\% & 41.7 & 21.4 & 5.81 & 6.50 & 2.82 & 0.96 & 0.80 & 0.30 & 0.22 & 0.26 & 16.5 \\
\hline
\end{tabular}

However, doping causes a slight decrease in some major element remains. It is varying quantitatively. There is also an increase in the content of alumina oxide in combination with increasing doping content (5.10 and $15 \%$ ). Its exceeds twenty percent $(20 \%)$.

2.2. Mineralogical analysis. The mineralogical analysis of crude and doped samples by Alumina at different percentages (5, 10 and 15\%), shows that kaolin, illite, quartz, dolomite and calcite are the main crystalline phases (Fig. 1).

The increase of the peak intensity of the kaolin doped marl can be explained by the incorporation of alumina in the silica tetrahedral site (Fig. 2). So, the intensity of the highest peak is manifested by a $15 \% \quad \mathrm{Al}_{2} \mathrm{O}_{3}$ doped marl. Furthermore, there is thus a continuous and positive correlation between increasing the $\mathrm{Al}_{2} \mathrm{O}_{3}$ content of the doping and the elevation of the peak intensity (Fig. 2). This result is conform with the results of chemical analysis. 


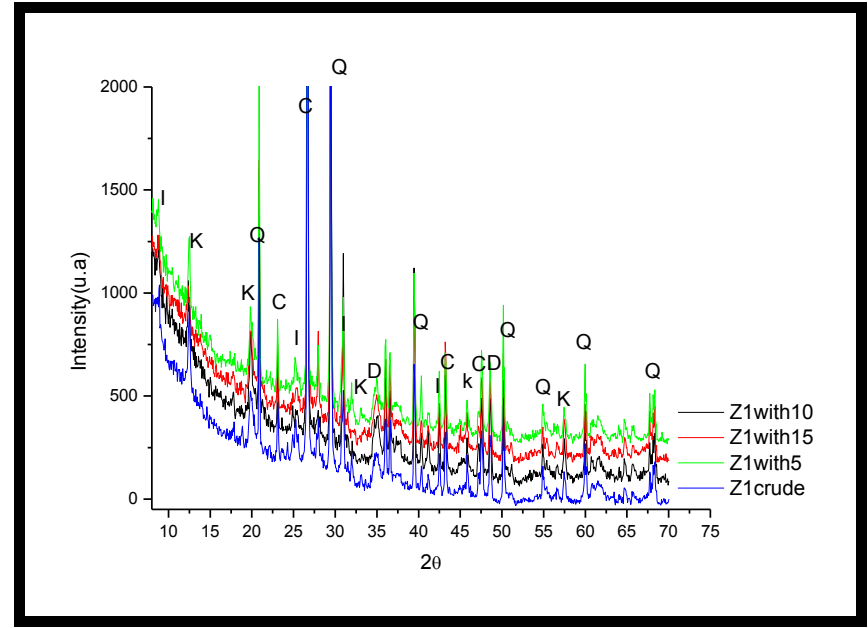

Fig.1: X-Ray of crude marl Z1 before and after doping with oxide alumina atdifferent percentages 5,10 and $15 \%$. With: $\mathrm{K}=$ kaolin, $\mathrm{Q}=$ quartz, $\mathrm{I}=$ Illite, $\mathrm{C}=$ calcite, $\mathrm{D}=$ dolomite.

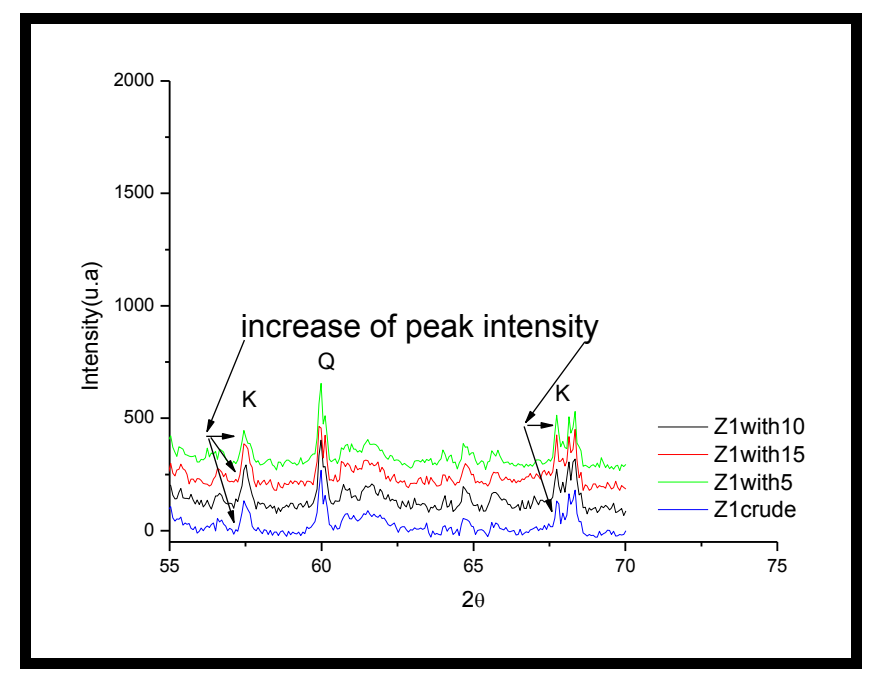

Fig. 2: X -Ray comparison of peaks intensity of Kaolin between crude and differently doped marls.

2.3. Technological testing (Atterberg limits). Based on the results of Table 1, we note the raw material $\mathrm{Z} 1$ has an average plasticity later increase with the level of doping. However the greater plasticity is observed in the doped marl with $15 \%$ alumina. 
The physico-mechanical characteristics of the clays in and after doping with metal oxide $\mathrm{Al}_{2} \mathrm{O}_{3} 107$

Therefore we can deduce that the doping of this marl with alumina oxide increases the plasticity of these materials. Previously this phenomenon was observed during handling.

Table. 2: The Results of Plasticity Analysis and Water Content in the Samples.

\begin{tabular}{|l|c|c|c|}
\hline Sample & Liquid Limit (Wl) & Plastic Limit (Wp) & Plasticity Index(Ip) \\
\hline Z1 brut & 43.2 & 19.40 & 23.79 \\
\hline Z1 doped with 5\% & 27.30 & 48.31 & 21.01 \\
\hline Z1 doped with $10 \%$ & 22.07 & 47.04 & 24.97 \\
\hline Z1 doped with15\% & 30.96 & 55.44 & 24.48 \\
\hline
\end{tabular}

Effect of Firing. During the rise of the firing temperature, the physicochemical transformations of the phase's marls affect the material (Fig.3). Each mineral in the mixture behaves as if it was alone .The decomposition products or new structural varieties, which take place under the influence of heat, react together to form new compounds (Mesrar and al., 2014).

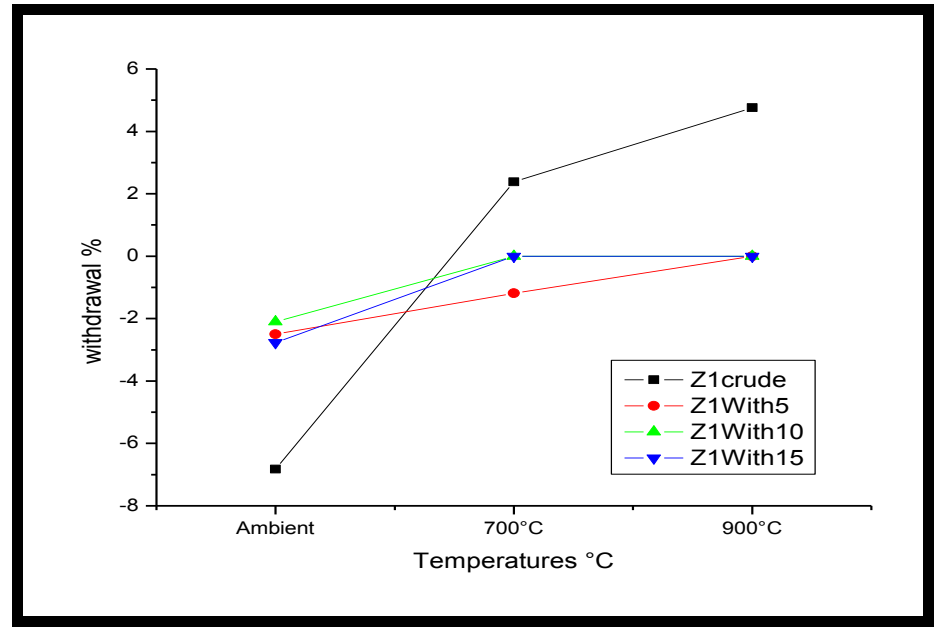

Fig. 3 - Evolution the withdrawal of raw samples and doped according to the firing temperature.

However, upon baking, the initial crystalline minerals disappeared and make space in varying proportions to an amorphous phase and new minerals (Baccour and al, 2011). Shrinkage accompanies this solid reaction, and is associated with changes in porosity and particle size. The proportions of the clay phase and / or associated minerals play an important role in these changes as well as the particle size (El Yakoub and al, 2006). Removing charged in the raw material is very 
important. This is due to the expansion case by new neoformed minerals (Trimdade, 2009).

In this study all doped materials has attended a withdrawal reduction until its cancellation. Therefore be concluded the doping plays a role in limiting internal withdrawal.

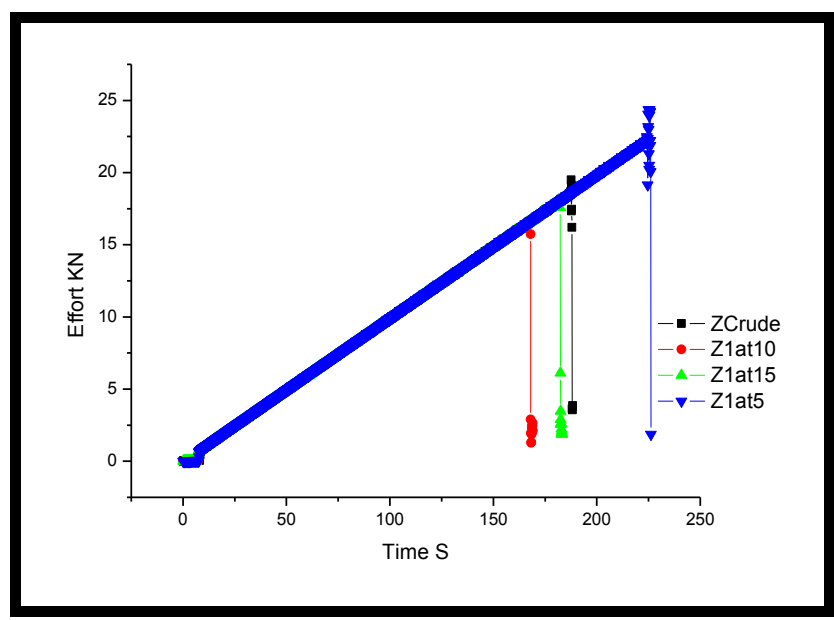

Fig. 4 - The Firing Impacts on the samples characteristics: loss on ignition and compression strength for the temperature $900^{\circ} \mathrm{C}$.

The marl doped $5 \%$ of $\mathrm{Al}_{2} \mathrm{O}_{3}$ have a relatively high resistance up to $25 \mathrm{KN}$ compared with bricks doped $10 \%$ and $15 \% \mathrm{Al}_{2} \mathrm{O}_{3}$ (Fig.4). We find that the effect of doping alumina is obvious. Indeed, the higher content of doping increasing the mechanical strength of bricks decreases. This resistance is in fact related to the increase of the porosity induced by the increase of the content of the doping (Khalfaoui, 2009). This causal relationship is in full agreement with the results obtained in the study of the porosity of the bricks (Mesrar and al, 2013).

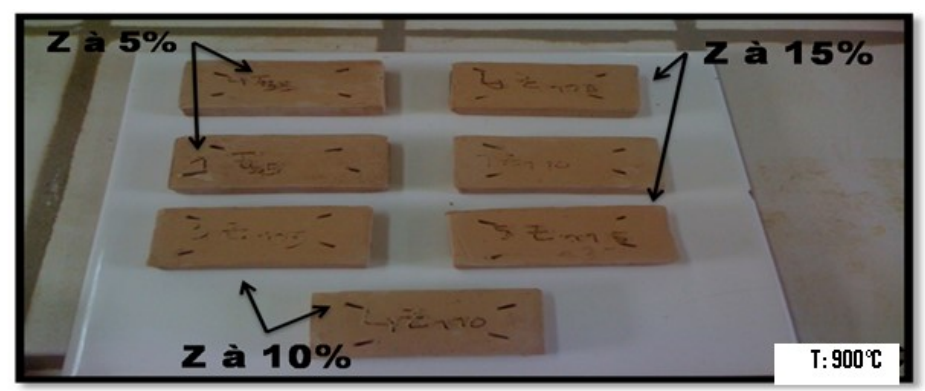

Photo.1. Color of fired bricks at $900^{\circ} \mathrm{C}$, after doping with various percentage of $\mathrm{Al}_{2} \mathrm{O}_{3}$. 
The physico-mechanical characteristics of the clays in and after doping with metal oxide $\mathrm{Al}_{2} \mathrm{O}_{3} 109$

Color after firing. The color is a parameter highly sought by ceramics and construction industry (Ferrari, 2006) and its evaluation is very important (Karfa, 2007).

Compared to raw bricks color our materials after firing, has been modified. Indeed, in all the doped bricks 5, 10 and 15\%, the color changes from light brown to beige cream in all firing temperatures (Phot.1).

\section{Conclusion}

The results of chemical analysis showed the higher rate of $\mathrm{Al}_{2} \mathrm{O}_{3}$ doping increases, its content increases in the marl. Mineralogical analysis indicated the presence of illite and kaolin clay minerals such as essential clay .The intensity of kaolin peaks increase with increasing doping level. This can be attributed to the combination of alumina with free silica of kaolin.

Technological tests showed suitable industrial properties of these marls, their doping with aluminum oxide induced an increase in their plasticity. The alumina acts as a degreaser and decrease shrinkage. However, the withdrawal response is correlated with the content of $\mathrm{Al}_{2} \mathrm{O}_{3}$ doping. Indeed, the degreaser plays the role of internal framework and limits the withdrawal.

The mechanical resistance of the doped bricks marl is independent of quantity $\mathrm{Al}_{2} \mathrm{O}_{3}$ doping. The marl doped with $5 \% \mathrm{Al}_{2} \mathrm{O}_{3}$ have a relatively high resistance compared with bricks doped with $10 \%$ and $15 \% \mathrm{Al}_{2} \mathrm{O}_{3}$. So, additional content of doping decreases mechanical strength of bricks.

This resistance is in fact related to the increase of the porosity induced by the increase of the content of the doping. This causal relationship is in full agreement with the results obtained in the study of the porosity of the bricks. The bricks of marls fired at $900^{\circ} \mathrm{C}$ and doped with $5 \%$ gives better mechanical strength of up to $25 \mathrm{kN}$. So, suggesting the use of this composite in ceramics, in construction and in pottery. Other more, the bricks provide a nice creamy beige color at $900^{\circ} \mathrm{C}$.

Acknowledgement. The study benefits from several individuals and institutions support in the USMBA and CNRST. X-ray analyzes and Chemical analyzes were carried out at CNRST Rabat.

\section{References}

Baccour, A. Zghal, A. Medhioub, M et Mhiri T,. (2011). Caractérisation physicochimique et mécanique de matériaux céramiques obtenus à partir des argiles tunisiennes, Verres, Céramiques/Composites Vol.1. N², pp 25-33.

El Yakoubi, N. Aberkan, M. Ouadia, M., (2006). Potentialité d'utilisation d'argiles marocaines de Jbel Kharrou dans l'industrie céramique, 338, Géomatériaux, 693-702. 
Esharghawi A, (2009). Élaboration de matériaux poreux à base de mullite par procédé SHS, docteur de l'université de limoges, discipline. Chimie-Chimie Physique, p :109.

Fabri, B., Fiori, C., (1985). Clays and complementary raw materials for stoneware tiles. Mineral. Petrogr. Acta 29, 535-545.

Ferrari S., (2006). The use of illitic clays in the production of stoneware tile ceramics Applied Clay Science 32 (2006) 73-81.

Jouenne. C.A, (1984). Traité de céramiques et de matériaux minéraux. Ed. Septima, Paris, (1984), 620p.

Karfa, T., (2007). Caractérisation physicochimique et mécanique de matériaux céramiques obtenus à partir d'une argile kaolinitique du Burkina Faso, C. R. Chimie 10, p 511et 517.

Khalfaoui, A., (2009). A Chloritic-illitic clay from Morocco: Temperature-timetransformation and neoformation, Applied Clay Science $45 \mathrm{p} \mathrm{83-89.}$

Louet. N,. (2003). Influence du dopage a la silice ou a l'oxyde de calcium sur le frittage et sur l'évolution microstructurale d'une alumine-alpha ultra pure, docteur de l'université de Lyon. Spécialité: génie des matériaux, p : 229

Mesrar .L, El Aroussi O., Lakrim M., Lahrach A., Chaouni A., et Jabrane R. (2013) Technological valorisation of the miocene clay in the region of Fez (Marocco) : caracterisation and exploitation possibilities. Present Environment and Sustainable Development (PESD), VOL. 7, no.1, 311-317p.

Mesrar L., Chahboun A,. Lamcharfi T,. Elbasset A,. and Jabrane R,(2012). Characterization of Miocene Marl of Fez Regions of Marocco after doping with $\mathrm{MnO}_{2}$. Clay Recearch, Vol, 31, No. 2, 79-83 p.

Mesrar L., Mesrar H, and Jabrane R. (2014)-Preparation and characterization of Miocene clay powders in the region of Fez (Morocco) after doping with metal oxides $\mathrm{Al}_{2} \mathrm{O}_{3}$. Journal of Computer Science and Engineering Research (JCSER), Volume (2), $1-4 \mathrm{p}$.

Trimdade, M.J., (2009). Transformations of calcareous rich clays with firing: a comparative study between calcite and dolomite, Applied Clay Science 42 (2009) 345355 . 